Discussion Papers of the

Max Planck Institute for

Research on Collective Goods

2020/13

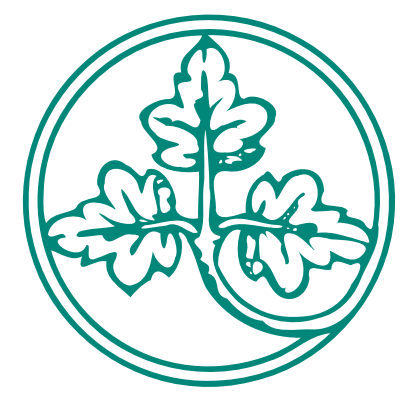

Discrimination, narratives and family history: An experiment with Jordanian host and Syrian refugee children

Kai Barron

Heike Harmgart

Steffen Huck

Sebastian Schneider

and Matthias Sutter 


\section{Discrimination, narratives and family history: An experiment with Jordanian host and Syrian refugee children}

Kai Barron / Heike Harmgart / Steffen Huck / Sebastian Schneider / Matthias Sutter

June 2020 


\title{
Discrimination, narratives and family history: An experiment with Jordanian host and Syrian refugee children *
}

\author{
Kai Barron ${ }^{\dagger}$, Heike Harmgart ${ }^{\ddagger}$, Steffen Huck\# ${ }^{\#}$, Sebastian Schneider§${ }^{\S}$ and Matthias \\ Sutter $^{+}$
}

\begin{abstract}
We measure the prevalence of discrimination between Jordanian host and Syrian refugee children attending school in Jordan. Using a simple sharing experiment, we find only little discrimination. Among the Jordanian children, however, we see that those who descended from Palestinian refugees do not discriminate at all, suggesting that a family history of refugee status can generate solidarity with new refugees. We also find that parents' narratives about the refugee crisis are correlated with the degree of discrimination, suggesting that discriminatory preferences are being transmitted through parental attitudes.
\end{abstract}

JEL-codes: C91, D90, J15, C93, J13

Keywords: Discrimination, refugees, children, experiment, integration

* We would like to thank Noura Shahed, Nedjma Koval and the entire INTEGRATED team for excellent help in conducting this experiment. The project has been approved by the Research Ethics Review at Wissenschaftszentrum Berlin (No. 2019/1/61) and pre-registered at the AEA RCT Registry as Trial 4063 prior to data collection, see https://doi.org/10.1257/rct.4063-1.0. Financial support from Deutsche Forschungsgemeinschaft (DFG, German Research Foundation) under Germany's Excellence Strategy - EXC 2126/1390838866 is gratefully acknowledged.

† Wissenschaftszentrum Berlin, Reichpietschufer 50, D-10785 Berlin, Germany. Email: kai.barron@wzb.eu.

$\ddagger \quad$ European Bank for Reconstruction and Development, London, UK, and Wissenschaftszentrum Berlin, Reichpietschufer 50, D-10785 Berlin, Germany. Email: Heike.harmgart@ebrd.com.

\# Wissenschaftszentrum Berlin, Reichpietschufer 50, D-10785 Berlin, Germany, and University College London, Gower Street, London, UK. Email: steffen.huck@wzb.eu

$\S \quad$ Max Planck Institute for Research on Collective Goods, Kurt-Schumacher-Strasse 10, D-53113 Bonn, Germany. Email: sschneider@coll.mpg.de.

$+\quad$ Max Planck Institute for Research on Collective Goods, Kurt-Schumacher-Strasse 10, D-53113 Bonn, Germany, and University of Cologne, Albertus-Magnus-Platz, D-50935 Cologne, Germany. Email: matthias.sutter@coll.mpg.de. 


\section{Introduction}

Since the outbreak of the Syrian Civil War in 2011 over 650,000 Syrian refugees have sought shelter in Jordan and registered with UNHCR ${ }^{1}$. The resulting sudden increase in the population size of around $10 \%$ has put enormous strain on Jordan's resource-poor economy, in particular on its water resources, waste management, housing stock, and the labor market (see, among others, Proktor 2014, Stave and Hillesund 2015, Francis 2015, and Razzaz 2017). ${ }^{2}$

With the war dragging on, 2019 was the ninth year of the conflict and most Syrian refugees in Jordan had no plans to return to Syria. The majority appear likely to stay for decades to come ${ }^{3}$ - just as previous refugees from Iraq and, above all, Palestine did. Their successful integration into Jordanian society has thus become a matter of prime importance for the country's stability in a fragile region.

We investigate two factors that may generate frictions for the integration of refugees into society: (i) the prevalence of discrimination in both the refugee and the host population, and (ii) the perception of facts and prevailing narratives pertaining to the consequences of the refugee influx. We study discrimination among Syrian and Jordanian children who, in all likelihood, will have to live together in Jordan for the long run. Since economic preferences seem to develop early in life (e.g., Fehr, Bernhard and Rockenbach 2008) and discrimination across different (ethnic or language) groups has been shown to emerge fairly early on (see, e.g., Bindra, GlätzleRützler, and Lergetporer 2020), studying discrimination by and against refugee children will help to better understand the roots of potential discrimination and may thus inform possible policy interventions for successful integration. Besides studying children's discriminatory behavior, we examine their parents' narratives about the consequences of Syrian immigration and can hence assess the influence of parents' attitudes on their children's degree of discrimination. Complementing our analysis of parental attitudes, we study whether a family history of refugee status can generate solidarity with new refugees. We do this by evaluating the influence of being a descendant of Palestinian refugees on discriminatory behavior.

In our experiment, we study two sharing tasks and one allocation task with a total of 456 children, aged 9 to 10 years. A novel feature of our study is that we can explore discrimination both against and by refugee children in a naturally arising, controlled and symmetric setting, namely that of Jordanian double-shift schools. Such schools are effectively operating two schools under one roof - one in the morning for Jordanians and one in the afternoon for Syrians (Albert et al. 2017). More than 200 double-shift schools were established in Jordan to manage the integration of Syrian refugee children into its education system. We ran the experimental sessions within such double-shift schools with children from the morning and the afternoon shift, allowing us to measure their social preferences towards their in-group and out-

1 The Jordanian government reports that they host a total of 1.4 million Syrian refugees as many have not been registered.

2 A dissenting view is presented in Fallah, Krafft, and Wahba (2019) who estimate the impact of the refugee influx on the labor market outcomes of Jordanians using panel data from 2010 to 2016 and report that Jordanians in areas with higher concentrations of refugees experienced no worse labor market outcomes than those in areas with lower concentrations.

3 A scenario-based analysis on Syrian refugee return patterns can be found in Onder and Sayed (2019). 
group. In addition, we collected survey data from all children and a large subset of their parents in order to assess the influence of some relevant aspects of the child's family background.

To the best of our knowledge our study is the first to explore discriminatory choice behavior against and by refugee children in an experimental setting. Note also that in our setting ethnic differences between the refugee and host population are comparatively small and that there are no language barriers. As such, our study comes close to identifying a pure refugee status effect on discrimination.

Overall, we find that discrimination in both populations is strikingly low while overall levels of generosity are remarkably high. However, there are several intriguing details. First, looking at the host country's children, we find significant differences in behavior between Jordanian children with and without Palestinian roots. While Jordanian children without Palestinian roots do display significant discrimination in favor of their in-group (and against the out-group comprising Syrian refugee children), we find that Jordanian children with Palestinian roots (whose parents, grandparents or great-grandparents were themselves refugees) do not discriminate at all between Jordanians and Syrians. While one may attribute this to a strong and shared refugee identity, note that this is by no means self-evident as more settled refugees or migrants have been reported to turn against newcomers. ${ }^{4}$

Second, when we examine drivers of discrimination, we find a tight link between parents' narratives and children's discriminatory behavior for the Syrian (refugee) children. This suggests that discriminatory preferences are being transmitted through repeated narratives at home. More precisely, if Syrian parents think that Jordanians should do everything they can to help Syrian refugees in this humanitarian crisis, their children show a significantly larger degree of discrimination.

Third, we also find evidence in favor of the contact hypothesis according to which ethnic conflict is ameliorated by social exposure to others (Allport 1954, Amir 1969, Corno, Burns and La Ferrara 2018, Paluck, Green and Green 2018, Rao 2019). In our Syrian sample, having more friends from the out-group reduces discrimination.

Our paper contributes to several strands of literatures. First, it builds on the work studying the formation of pro-social preferences in children (e.g. Fehr, Bernhard, and Rockenbach 2008, Fehr, Glätzle-Rützler, and Sutter 2013, Cavatorta, Zizzo, and Daoud 2020). The evidence for discriminatory behavior by kindergarten and pre-school students is somewhat mixed. List, List and Samek (2017) find no discrimination by three to five-year olds, while Bindra, GlätzleRützler, and Lergetporer (2020) show that out-group discrimination emerges in a group of three to six-year olds and increases with age. Our experimental subjects' age group of 9 to 10 years

4 See, for example, Vila (2000), Moukarbel (2009), or Kalupe (2018). Further, Wilkes and Wu (2019) argue that the experience of being an immigrant, and being the subject of discrimination, can lead to a reduction in generalized trust. In general, the arrival of new immigrants or refugees can activate different responses by existing immigrant minorities. It can either induce the existing minority to distance themselves from the new arrivals and to try to assimilate more with the majority (see, e.g., Fouka, Mazumder, and Tabellini 2020), or, alternatively, it can prompt them to draw parallels with their personal family history which can induce increased empathy towards the new arrivals (Dinas, Fouka, and Schläpfer, 2019 and Williamson et al. 2020). Note, however, that these studies all examine attitudes expressed by adults. 
is most comparable to the studies by Angerer et al. $(2016,2017)$, which focus on primary school children (aged 7 to 11). They find discriminatory behavior among these primary school children from different language groups in Northern Italy. Yet none of the previously mentioned papers concerns refugee children or their parents' attitudes towards the host country. A recent paper by Alan et al. (2020) is also related to our study. They study the integration of Syrian refugees in Turkey. The authors provide evidence that a perspective-taking intervention in schools where approximately one in five children are refugees lowers peer violence, social exclusion and ethnic segregation, thereby promoting pro-social behavior. They also study giving behavior but only explore whether there are differences in giving to a random recipient or a Syrian refugee child. They do not examine differences in behavior between refugee and host children and cannot explore the role of parents' narratives for discrimination or whether children have a family history of refugee status, both of which are central contributions that we make to this literature on the economic preferences of children.

Second, we relate to the literature studying refugee integration and the reaction of local communities to the sudden arrival of refugees. Several recent papers have studied the impact of refugee arrivals, showing, for example, that local Swedish residents avoided reading positive news about refugees (Freddi 2018). Exposure to refugees did not increase right-wing support in Germany (Schaub, Gereke, and Baldassarri 2019) and decreased it in Italy (Gamalerio et al. 2019). In Northern Lebanon, increasing the salience of the "refugee crisis" reduced locals' trust and prosocial preferences towards refugees (Hager and Valasek 2020) although this was ameliorated by actual contact between members of the refugee and host population. ${ }^{5}$ Alrababa'h et al. (2018) provide evidence complementary to ours, showing that personal exposure to economic impacts resulting from the refugee crisis is not associated with anti-refugee sentiments among natives in Jordan. Yet all these studies relate to adult behavior and attitudes. For these adults, the inflow of refugees interacts with pre-existing attitudes to precipitate potential discriminatory behavior. In contrast, we study children who have grown up in the middle of the refugee crisis, which has spanned their formative years, and we ask how this has influenced the development of their pro-social preferences, specifically those relating to discrimination, as the latter can create a severe impediment for integration.

In the following section, we present the background to our study and describe the experimental design and procedures. Results are presented in Section 3, and Section 4 concludes the paper.

\section{Experimental Setting, Design and Procedures}

The setting of our study, the Kingdom of Jordan, is geopolitically very important but also, at the same time, admittedly rather special due to its long history of absorbing refugees. Circassian immigration during the Ottoman occupation in the $19^{\text {th }}$ century was the first notable wave, while Palestinians who lost their homelands in the Arab-Israeli wars formed the largest single 
contingent. Since the influx of Syrian refugees, Jordanians have been internationally commended for their generosity in hosting the Syrian refugees of which fewer than $20 \%$ live in camps. Jordan provides subsidized health care ${ }^{6}$ for all registered refugees and free schooling for all children, with children making up around half of the Syrian refugee population. Regular schooling has been achieved by establishing over two hundred double-shift schools that effectively operate two schools under one roof - one in the morning for Jordanians, one in the afternoon for Syrians (Albert et al. 2017).

We conducted the experiment in 13 of these double-shift schools, all situated in the north of Jordan where the majority of Syrian refugees reside. In all, we had 456 participating children, 232 from the morning shift and 224 from the afternoon shift. Additionally, we succeeded in surveying 395 parents (one per child; covering $87 \%$ of the 456 children), 187 Jordanian parents of children from the morning shift, and 208 Syrian parents of children from the afternoon shift. ${ }^{7}$

In the experiment, we implemented a sequence of three tasks. ${ }^{8}$ In each of the first two tasks subjects had to allocate five toys between themselves and another, anonymous child. In one task, the other child was from the same shift; in the other task, the other child was from the other shift. The sequence was randomized but as we do not find meaningful order effects ${ }^{9}$, we will report results using the pooled data below. In addition, we varied the salience of the two group identities in the instructions. In one condition we simply referred to children from the morning and afternoon shifts; in another we added the reminder that there are mainly Jordanian children in the morning shift and mainly Syrian children in the afternoon shift. This variation had no effect on behavior, from which we conclude that all children are perfectly aware of who attends the morning and afternoon shifts. This is not that surprising as the daily shift change features very prominently in the school routine, with one shift marching out of school while the next shift is approaching it (see Albert et al., 2017, where a video of the shift change can be found). In our results section below we focus on the pooled data.

In the third task, a third-party allocation task, subjects had to allocate five toys between another child from the same shift and a child from the other shift, with both children unknown to the

6 Under severe financial duress, the Jordanian government had to reduce subsidies in early 2018. The fee for an emergency check-up is, however, still below JD 10 (approx. USD 14).

7 To be precise, it is not the case that all children in the morning shift are Jordanian and all children in the afternoon shift are Syrian. In our parent survey, 95\% of morning shift parents report being Jordanian (and $2.7 \%$ Syrian), while $88 \%$ of the afternoon shift parents report being Syrian (and $7.7 \%$ Jordanian). In our analysis we keep the full samples because non-Jordanian children attending the morning shift are already more integrated into Jordanian society and non-Syrian children in the afternoon are also likely to have a refugee background. Our results are robust to the exclusion of these children. In the text below we shall, for the sake of expositional simplicity, refer to the children in the morning shift simply as Jordanians, and to children in the afternoon shift simply as Syrians.

$8 \quad$ All tasks and rewards were piloted in a different double-shift school one week before the actual experiment. This allowed us to ensure that the children enjoyed receiving the different toys and to adjust the difficulty of the last task. After the three tasks described in detail here, we implemented a fourth task measuring grit in the spirit of Duckworth et al. (2007) and Alan, Boneva, and Ertac (2019). We do not report the results from this task here as they are orthogonal to the focus of this paper and unrelated to issues of discrimination.

For example, when we consider our main comparisons of giving behavior (as in Table 1) and use a regression analysis to interact these decisions with a variable that denotes the order of decisions, all the interaction coefficients are insignificant. 
subject. They received five additional toys for themselves for completing this task, independently of their choice.

In all three tasks, we opted to have an odd number of toys to remove the possibility of a 50-50 split. Güth, Huck, and Müller (2001) show that equal splits have an appeal to participants over and above pure fairness considerations due to their focal nature. Of course, this forces subjects to favor one side over the other in each of the three tasks.

All the children also completed two surveys which were part of a larger educational program financed by UNICEF and administered by Integrated International, an Amman-based consultancy specialized in program implementation and evaluation. Our experiment took place halfway between these two surveys.

We conducted the experiment with the help of thirteen thoroughly trained enumerators. All enumerators had worked with Integrated International before and were experienced in administering surveys to children. Children were taken out of their classrooms to do the tasks oneon-one with the enumerators. This helped to ensure that the children fully understood the tasks and were not influenced by the other children in their class. Choices in the sharing tasks were made directly with the toys. After children had chosen their preferred allocation, the toys were put into A5-sized envelopes. The name of the decision-making child was written on one of the envelopes, while the envelopes for the passive receiving children remained blank. Note that the receiving children were different from the active decision-making children and that this was known to the active children; that is, they knew that they would not receive any rewards in addition to the rewards they received from their own choices. All envelopes were distributed at the end of the school day (or the following day in case decisions made in the afternoon were relevant for morning recipients). For more details on the procedures, see Appendix B.

\section{Results}

\subsection{Children's Behavior: Main Descriptive Statistics}

Table 1 summarizes the main descriptive statistics for the first three tasks and also provides some simple test statistics. The first column shows the average amounts given to the other child when the other child was in the same shift (giving to the in-group) and the second column shows the average amounts given to the other child when the other child was in the other shift (giving to the out-group). The third column shows test statics for the comparison between giving to the in- and out-group. The fourth column shows the average amount allocated to a child from the other shift in the third task in which participants divided five toys between someone from their own shift and another child from the other shift. 
Table 1: Descriptive statistics and hypothesis tests for the first three tasks.

\begin{tabular}{|c|c|c|c|c|c|}
\hline & Task 1 and 2 & Tasks 1 and 2 & $p($ Diff $>0)$ & Task 3 & $\mathrm{~N}$ \\
\hline & Giving to & Giving to & & Allocation to & \\
\hline & In-Group\# & Out-Group\# & & Out-Group ${ }^{+}$ & \\
\hline Morning Shift & 2.35 & 2.25 & 0.043 & 2.28 & 232 \\
\hline (Jordanians) & $(0.67)$ & $(0.69)$ & & $(0.56)$ & \\
\hline Afternoon Shift & 2.43 & 2.35 & 0.076 & 2.25 & 224 \\
\hline (Syrians) & $(0.69)$ & $(0.59)$ & & $(0.63)$ & \\
\hline$p($ Diff $\neq 0)$ & 0.19 & 0.10 & $-0.016 \ddagger / p=0.84$ & 0.53 & \\
\hline
\end{tabular}

Notes: Standard deviations in parentheses.

\# Children were given five toys to distribute between themselves and another child in the respective shift. The figures in these columns report how many out of those five toys were given to the other child (with the rest kept by the decision-making child).

${ }^{+}$Children had to allocate five toys between a child from their own shift and a child from the other shift. The figures report how many toys were given to the child from the other shift (with 5 minus this figure given to the child from their own shift on average).

$\ddagger$ This figure indicates the difference between the two shifts with respect to the difference between in-group and out-group allocation in tasks 1 and 2 . It is not significant.

We make the following observations.

(1) Our subjects, from both the morning and the afternoon shifts, are unusually generous. All relevant models of social preferences (such as Fehr and Schmidt, 1999, Bolton and Ockenfels, 2000, or Charness and Rabin, 2002, to name just a few) suggest that subjects will allocate at least 3 toys to themselves since disadvantageous inequality is assumed to hurt more than advantageous inequality. This means that on average we should see at most 2 toys being allocated to the other child. In contrast, what we observe is that the recipient children get between 2.25 and 2.43 toys on average. We observe $41.1 \%$ [resp. $33.0 \%$ ] of subjects in the morning shift allocating more to the other child than to themselves when the recipient is in the in- [out-] group. The corresponding numbers for the afternoon shift are $45.3 \%$ [42.7\%].

(2) While discrimination is (partly) statistically significant, the magnitudes of the differences between giving to the in- and out-group are small ( 0.1 for the morning shift, 0.08 for the afternoon shift). The level of discrimination is indistinguishable between Jordanian and Syrian children (as a $p$-value of 0.84 indicates).

(3) In the third-party allocation task subjects make, on average, choices that are very similar to their choices in tasks 1 and 2 where self-interest is involved. Specifically, they treat a child from the same shift versus a child from the other shift similarly to how they treat themselves versus another child. Notice, however, that again the average allocated to the other shift is above 2 for both the morning and afternoon shifts. In the morning shift, $28.1 \%$ of subjects favor the child from the other shift over the child from their own shift; in the afternoon it is $25.9 \%$. Again, we see no differences between Jordanian and Syrian children in the third-party allocation task $(p=0.53)$. 


\subsection{Parents' Narratives}

When communities or entire nations experience a departure from life as usual (e.g. due to a refugee crisis), the collective effort to make sense of events often results in multiple narratives being propagated through society (see, e.g., Boudes and Laroche 2009, Innes 2010, Blinder and Allen 2016, Greussing and Boomgaarden 2017, Eberl et al. 2018). It is plausible that a parent's interpretation of the refugee crisis and its impact on daily life is transmitted to their children, thereby influencing whether they display discriminatory sharing behavior. To provide evidence on this, we collected measures of the parents' perceptions of the crisis. In particular, we asked parents to assess their agreement with the following four statements on a scale from 1 (totally disagree) to 10 (totally agree):

i. "The Syrian crisis is a tragedy, and Jordanians should do everything they can to help the Syrian refugees, irrespective of the costs."

ii. "Jordanians have already done so much for the Syrian refugees; it is time for other countries to do more to help."

iii. "The Syrian crisis has increased housing rental prices in Jordan."

iv. "The Syrian crisis has made it more difficult to find jobs in Jordan."

Table 2: Parents' perceptions of the refugee crisis: Average agreement on a scale from 1 (totally disagree) to 10 (totally agree)

\begin{tabular}{lccc}
\hline Perception & $\begin{array}{c}\text { Morning Shift (Jor- } \\
\text { danians) }\end{array}$ & $\begin{array}{c}\text { Afternoon Shift } \\
\text { (Syrians) }\end{array}$ & $\mathrm{p}$ (Diff $\neq 0$ 0) \\
\hline (i) Jordanians morally obliged & 7.4 & 8.1 & $<0.01$ \\
to help & $(2.2)$ & $(1.9)$ & 0.22 \\
(ii) Jordan has done enough & 8.7 & 9.0 & 0.04 \\
(iii) Rental prices increased & $(1.8)$ & $(1.6)$ & 0.72 \\
& 8.2 & 8.6 & $(1.8)$ \\
(iv) Jobs more difficult to find & $(2.1)$ & 8.0 & $(2.2)$ \\
\hline $\mathrm{N}$ & 7.9 & 208 & \\
\hline
\end{tabular}

Notes: Standard deviations in parentheses.

Table 2 summarizes the average response to each of these questions by the parents of Jordanian and Syrian children (the full distributions are shown in Figure A.1 in Appendix A). The main observation is that, overall, the two groups of parents share a relatively similar understanding of the crisis. One major difference is observed in the degree to which the parents assess the refugee crisis as being a tragedy implying a moral imperative that Jordanians should do everything they can to assist. On this dimension, Syrian parents are more strongly in favor than their Jordanian counterparts. However, both sets of parents agree to the same 
degree that Jordanians have done enough to help and that jobs are more difficult to find as a consequence of the Syrian crisis. Both groups find themselves agreeing that housing prices increased as a consequence of the crisis, with a slightly but significantly stronger sentiment measured for the Syrians which is probably due to a larger fraction of renters among them.

\subsection{Covariates of Discrimination: The Role of Parents' Narratives, Family History, and Social Contact}

Although, on average, children do not discriminate a lot between their in- and out-group in our data, we want to understand how discrimination depends on various covariates. In particular, we want to examine the role of parents' narratives of the refugee crisis, the impact of a family history as refugees, and the relevance of the contact hypothesis (Allport 1954, Amir 1969) which predicts less discrimination by those who are exposed to more contact with the outgroup.

For this purpose, we regress an overall measure of discrimination obtained from our three tasks on children's characteristics and their parents' narratives. Specifically, to construct our discrimination measure, we sum the following two objects: (i) the difference between the amount given to a recipient from the in-group and the amount given to a recipient from the outgroup in tasks 1 and 2, and (ii) the difference between the amount allocated to an in-group child and the amount allocated to an out-group child in task 3 (divided by 2).

Table 3: Covariates of Discrimination for Jordanian Children

\begin{tabular}{|c|c|c|c|c|c|c|}
\hline \multirow[b]{3}{*}{ Time going to that school (yrs) } & \multicolumn{6}{|c|}{ Dependent variable: Discrimination (Jordanian Children, Morning Shift) } \\
\hline & \multicolumn{2}{|c|}{ [1] Contact } & \multicolumn{2}{|c|}{ [2] Parental Perceptions } & \multicolumn{2}{|c|}{ [3] Full Model } \\
\hline & 0.026 & $(0.083)$ & & & 0.014 & $(0.081)$ \\
\hline Outgroup-friends at school $(=1)$ & -0.035 & $(0.177)$ & & & -0.059 & $(0.195)$ \\
\hline Number of outgroup-friends & 0.053 & $(0.129)$ & & & 0.045 & $(0.126)$ \\
\hline Outgroup-friends at school $(=1)$ & -0.035 & $(0.136)$ & & & -0.010 & $(0.136)$ \\
\hline \multicolumn{7}{|l|}{$\times$ Number of outgroup-friends } \\
\hline Having Syrian relatives $(=1)$ & -0.609 & $(0.438)$ & & & -0.660 & $(0.441)$ \\
\hline Having Palestinian roots $(=1)$ & $-0.322^{\star \star}$ & $(0.151)$ & & & $-0.347 \star \star$ & $(0.153)$ \\
\hline Jordanians have to help & & & 0.025 & $(0.039)$ & 0.035 & $(0.041)$ \\
\hline Jordan has done enough & & & -0.025 & $(0.045)$ & -0.063 & $(0.048)$ \\
\hline Rental prices increased & & & 0.058 & $(0.039)$ & 0.062 & $(0.039)$ \\
\hline Jobs more difficult to find & & & -0.032 & $(0.031)$ & -0.032 & $(0.030)$ \\
\hline Constant & $0.433^{\star \star}$ & $(0.213)$ & 0.132 & $(0.412)$ & 0.510 & $(0.522)$ \\
\hline Wald test: F statistic (p-value) ${ }^{a}$ & 2.24 & $(.137)$ & .1 & $(.752)$ & & \\
\hline $\mathrm{R}^{\wedge} 2$ & 0.045 & & 0.018 & & 0.068 & \\
\hline Observations $^{b}$ & 178 & & 187 & & 178 & \\
\hline
\end{tabular}

Robust standard errors in parentheses

a Column [1] reports results for testing the linear combination "Outgroup-friends at school $(=1)$ " + "Number of outgroup-friends" + "Outgroup-friends at school $(=1)$ x Number of outgroup-friends" + "Having Syrian relatives $(=1)$ " = 
0. Column [2] reports results for testing the linear combination "Jordanians morally obliged to help" - "Jordan has done enough" - "Rental prices increased" - "Jobs more difficult to find" = 0.

${ }^{b}$ Nine parents did not indicate either whether they had Syrian relatives or Palestinian roots, which explains the lower number of observations in some columns.

$\star p<.1,{ }^{\star *} p<.05, * \star * p<.01$

Table 3 shows our estimation results for the morning shift (Jordanian children) and Table 4 for the afternoon shift (Syrian children). The first column in both tables contains estimates for the contact variables that we elicited when we were asking for the existence and number of friends from the outgroup. Moreover, for the Jordanians, we asked whether they have Syrian relatives or Palestinian roots, with the latter indicating a family history of having descended from refugees themselves. The second column contains parents' narratives and the third column combines the two.

Table 4: Covariates of Discrimination for Syrian Children

\begin{tabular}{|c|c|c|c|c|c|c|}
\hline \multirow[b]{3}{*}{ Time going to that school (yrs) } & \multicolumn{6}{|c|}{ Dependent variable: Discrimination (Syrian Children - Afternoon Shift) } \\
\hline & \multicolumn{2}{|c|}{ [1] Contact } & \multicolumn{2}{|c|}{ [2] Parental Attitudes } & \multicolumn{2}{|c|}{ [3] Full Model } \\
\hline & -0.081 & $(0.110)$ & & & -0.099 & $(0.109)$ \\
\hline Outgroup-friends at school $(=1)$ & 0.155 & $(0.221)$ & & & 0.061 & $(0.225)$ \\
\hline Number of outgroup-friends & $-0.042^{*}$ & $(0.024)$ & & & $-0.043^{*}$ & $(0.024)$ \\
\hline $\begin{array}{l}\text { Outgroup-friends at school }(=1) \\
\quad \times \text { Number of outgroup-friends }\end{array}$ & 0.033 & $(0.042)$ & & & 0.043 & $(0.045)$ \\
\hline Having Jordanian relatives $(=1)$ & -0.099 & $(0.207)$ & & & -0.112 & $(0.206)$ \\
\hline $\begin{array}{l}\text { Distance from origin to Amman (in } \\
100 \mathrm{~km} \text { ) }\end{array}$ & -0.047 & $(0.057)$ & & & -0.062 & $(0.056)$ \\
\hline Time in Jordan (yrs) & -0.029 & $(0.105)$ & & & -0.018 & $(0.103)$ \\
\hline Jordanians have to help & & & $0.082^{*}$ & $(0.046)$ & $0.086^{*}$ & $(0.051)$ \\
\hline Jordan has done enough & & & $-0.117 * \star$ & $(0.055)$ & $-0.122^{\star *}$ & $(0.061)$ \\
\hline Rental prices increased & & & 0.041 & $(0.047)$ & 0.047 & $(0.050)$ \\
\hline Jobs more difficult to find & & & $-0.070 * \star$ & $(0.035)$ & $-0.069 *$ & $(0.038)$ \\
\hline Constant & 0.888 & $(0.758)$ & $0.946 *$ & $(0.503)$ & $1.470 *$ & $(0.852)$ \\
\hline Wald testa: F statistic (p-value) & .003 & $(.955)$ & $5.648^{\star \star}$ & $(.018)$ & & \\
\hline $\mathrm{R}^{\wedge} 2$ & 0.020 & & 0.039 & & 0.064 & \\
\hline Observations ${ }^{b}$ & 174 & & 208 & & 174 & \\
\hline
\end{tabular}

Robust standard errors in parentheses

a Column [1] reports results for testing the linear combination "Time going to that school (yrs)" + "Outgroup-friends at school (=1)" + "Number of outgroup-friends" + "Outgroup-friends at school (=1) x Number of outgroup-friends" + "Having Jordanian relatives (=1)" - "Distance from origin to Amman (in 100km)" + "Time in Jordan (yrs)" =0. Column [2] reports results for testing the linear combination "Jordanians have to help" - "Jordan has done enough" - "Rental prices increased" - "Jobs more difficult to find" $=0$.

b For some parents we don't have information on their origin in Syria and whether or not they have relatives in Jordan, which explains the lower number of observations in some columns.

${ }^{*} p<.1,{ }^{*} p<.05, * \star * p<.01$ 
Three findings stand out from this exercise.

(1) Jordanian children with Palestinian roots discriminate significantly less against Syrians than other Jordanians. In fact, examining the estimates in detail, we find that Jordanian children with Palestinian roots do not discriminate at all. It appears that their shared refugee identity substantially increases solidarity with other refugee children. We consider this to be perhaps the most striking finding of our study.

(2) For the Syrian population we find a tight link between parents' narratives and children's discriminatory behavior with three of the four perception variables being significant and having signs in the directions one would expect. ${ }^{10}$ When parents think that "Jordan has done enough" and that, as a consequence of the refugee influx, "jobs are more difficult to find" their children discriminate less. On the other hand, if they agree more strongly with the statement that "the crisis is a tragedy, and Jordanians should do everything they can to help the Syrian refugees", their children discriminate more. For the Jordanian population we do not find such effects.

(3) There is some, but limited evidence for the contact hypothesis. Syrian children in the afternoon shift discriminate less when they have more out-group (i.e., Jordanian) friends. On the other hand, there is no evidence for the contact hypothesis in our sample of Jordanian children.

\section{Conclusion}

Our study shows that there is remarkably little discrimination among Jordanian and Syrian refugee children who attend double-shift schools in the Kingdom of Jordan. This is coupled with very high levels of generosity towards others. Both findings contrast sharply with similar experiments in Western settings (see, e.g., Sutter, Zoller, Glätzle-Rützler 2019 for a survey). One caveat of our results is that our experimental design does not allow us to isolate the underlying reason for this observed generosity (and thereby provide a complete explanation for the difference in relation to Western settings). However, a shared religion, culture and language, as well as Bedouin hospitality culture and the Kingdom of Jordan's history of absorbing and integrating refugees are all factors that may contribute to the striking pattern. ${ }^{11}$ Differentiating between these potential drivers of pro-social behavior in a cross-country setting could be an exciting avenue for future research.

The data collected from our experiment and the correspondent survey does, however, allow us to contribute to the understanding of the channels that drive differences in pro-social attitudes and non-discriminating behavior within the population we sample from (as opposed to explaining the high baseline level we observe throughout). For Syrian children we find that both con-

10 We conjectured that narratives that stress the burden refugees impose on Jordanians would reduce discrimination, while narratives that stress Syrian entitlement would increase discrimination. 
tact - as measured by the number of out-group friends - and narratives at homes - as measured by parents' narratives relating to the refugee crisis - shape discrimination. None of these measures are correlated with the behavior of the Jordanian children, pointing to a remarkable asymmetry between the refugee and host population. This asymmetry is perhaps not that surprising in light of the fact that the lives of the Syrian families in our sample have been much more dramatically altered than the lives of the Jordanian families. It appears plausible that narratives about the refugee situation play a more fundamental role for Syrians than for Jordanians and that making friends with "the others" is of more pronounced psychological and material importance for refugees than it is for hosts.

Perhaps most important is our key finding for the Jordanian population, where we observe that children with Palestinian roots do not discriminate at all against Syrian children. Clearly, family history (going back over fifty years) matters for the pro-social behavior of the children we observe. It appears that already our 9 to 10-year old subjects, whose parents, grand-parents or grand-grand-parents lost their homes in the 1948 or 1967 Arab-Israeli wars, have been instilled with a refugee identity that generates solidarity with other refugee children. 


\section{References}

Alan, S., Baysan, C., Gumren, M., and Kubilay, E. (2020) Building inter-ethnic cohesion in schools: An intervention on perspective-taking. Mimeo.

Alan, S., Boneva, T., and Ertac, S. (2019) Ever failed, try again, succeed better: Results from a randomized educational intervention on grit. Quarterly Journal of Economics 134, $1121-1162$.

Albert, P., Ellguth, P., Fels, M., Harmgart, H., and Huck, S. (2017) double-shift.org. A Multimedia Documentary. Berlin: WZB.

Allport, G. (1954) The nature of prejudice. New York, NY: Basic Books.

Alrababa'h, A., Dillon, A., Williamson, S. Hainmueller, J. Hangartner, D. and Weinstein, J. (2019) Attitudes toward migrants in a highly-impacted economy: Evidence from the Syrian refugee crisis in Jordan. IPL Working Paper Series 19 (1).

Alshoubaki, W., and Harris, M. (2018) The impact of Syrian refugees on Jordan: A framework for analysis. Journal of International Studies 11, 154-179.

Amir, Y. (1969) Contact hypothesis in ethnic relations. Psychological Bulletin 71, 319.

Angerer, S., Dutcher, G., Glätzle-Rützler, D., Lergetporer, P., and Sutter, M. (2017), Gender differences in discrimination emerge early in life: Evidence from primary school children in a bilingual city. Economics Letters 152, 15-18.

Angerer, S, Glätzle-Rützler, D., Lergetporer, P., and Sutter, M. (2016) Cooperation and discrimination within and across language borders: Evidence from children in a bilingual city. European Economic Review 90, 254-264.

Bertrand, M. and Duflo, E. (2017) Field experiments on discrimination. In: Banerjee, A. V., and Duflo, E. (eds.), Handbook of Economic Field Experiments Vol. 1, 309-393. Amsterdam: Elsevier.

Bindra, P. C., Glätzle-Rützler, D., and Lergetporer, P. (2020) Discrimination at young age: Experimental evidence from preschool children. Journal of Economic Behavior and Organization, 175, 55-70.

Blinder, S., and Allen, W. L. (2016) Constructing immigrants: Portrayals of migrant groups in British national newspapers 2010-2012. International Migration Review 50, 3-40.

Bolton, G., and Ockenfels, A. (2000) ERC: A theory of equity, reciprocity and competition. American Economic Review 90, 166-193.

Boudes, T., and Laroche, H. (2009) Taking off the heat: Narrative sensemaking in post-crisis inquiry reports. Organization Studies 30, 377-396. 
Cavatorta, E., Zizzo, D., and Daoud, Y. (2020) Does exposure to violence affect reciprocity? Experimental evidence from the West Bank. Mimeo.

Charness, G., and Rabin, M. (2002) Understanding social preferences with simple tests. Quarterly Journal of Economics 117, 817-69.

Corno, L., Burns, J., and La Ferrara, E. (2018) Interaction, stereotypes and performance. Evidence from South Africa. BREAD Working Paper no. 549.

Dinas, E., Fouka, V., and Schläpfer. A. (2019) Family History and Attitudes Toward Outgroups: Evidence from the European Refugee Crisis. Mimeo.

Duckworth, A., Peterson, C., Matthews, M. and Kelly, D. (2007) Grit: Perseverance and passion for long-term goals. Journal of Personality and Social Psychology 92, 1087-1101.

Greussing, E., and Boomgaarden, H. (2017) Shifting the refugee narrative? An automated frame analysis of Europe's 2015 refugee crisis. Journal of Ethnic and Migration Studies $43,1749-74$.

Fallah, B., Krafft, C., and Wahba, J. (2019) The impact of refugees on employment and wages in Jordan. Journal of Development Economics 139, 203-216.

Fehr, E., Bernhard, H., and Rockenbach,B. (2008) Egalitarianism in young children. Nature 454, 1079-1083.

Fehr, E., Glätzle-Rützler, D., and Sutter, M. (2013) The development of egalitarianism, altruism, spite and parochialism in childhood and adolescence. European Economic Review 64, 369-383.

Fehr, E., and Schmidt. K. (1999). A theory of fairness, competition, and cooperation. Quarterly Journal of Economics 114, 817-68.

Fouka, V., Mazumder, S., and Tabellini, M. (2020) From immigrants to Americans: Race and assimilation during the Great Migration. Mimeo.

Francis, A. (2015) Jordan's Refugee Crisis. Washington (DC): Carnegie Endowment for International Peace.

Freddi, E. (2018) Do people avoid morally relevant information? Evidence from the refugee crisis. Mimeo.

Gamalerio, M., Luca, M., Romarri, A., and Viskanic, M. (2018) Finding the warmth of other suns? Refugee reception, extreme votes and hate crimes. SSRN Working Paper 3277550.

Güth, W., Huck, S., and Müller, W. (2001) The relevance of equal splits in ultimatum games. Games and Economic Behavior 37, 161-169.

Hager, A. and Valasek, J. (2019) Refugees and social capital: Evidence from Northern Lebanon. WZB Discussion Paper SPII 2020-301. 
Innes, A. J. (2010) When the threatened become the threat: The construction of asylum seekers in British Media narratives. International Relations 24, 456-477.

Eberl, J., Meltzer, C., Heidenreich, T., Herrero, B., Theorin, N., Lind, F., Berganza, R., Boomgaarden, H., Schemer, C, and Strömbäck, J. (2018) The European media discourse on immigration and its effects: a literature review. Annals of the International Communication Association 42, 207-223.

Kalupe, H. (2018) Community-Based Organisations' Role in Refugee Integration: A Case Study in Kristiansand, Norway. Masters Thesis. http://hdl.handle.net/11250/2565634

List, A. J., List, J. A., and Samek, A. (2017) Discrimination among pre-school children: Field experimental evidence. Economics Letters, 157, 159-162.

Moukarbel, N. (2009) Sri Lankan housemaids in Lebanon: a case of 'symbolic violence' and 'everyday forms of resistance'. Amsterdam: Amsterdam University Press.

Onder, H. and Sayed, H. (2019) The Mobility of Displaced Syrians: An Economic and Social Analysis. World Bank Group. https://openknowledge.worldbank.org/bitstream/handle/10986/31205/9781464814013.pdf

Paluck, E., Green, S., and Green, D. (2019) The contact hypothesis re-evaluated. Behavioural Public Policy 3, 129-158.

Proktor, K. (2014) Tapped Out: Water Scarcity and Refugees Pressures in Jordan, Portland: Mercy Corps.

Rao, G. (2019). Familiarity does not breed contempt: Generosity, discrimination, and diversity in Delhi schools. American Economic Review 109, 774-809.

Razzaz, S. (2017) A Challenging Market Becomes Even More Challenging: Jordanian Workers, Migrant Workers and Refugees in the Jordanian Labour Market, Beirut: International Labour Organization.

Schaub, M., Gereke, J., and Baldassarri, D. (2019) Strangers in Hostile Lands: Exposure to Refugees and Right-Wing Support in Germany's Eastern Regions. Mimeo.

Stave, S.E., and S. Hillesund (2015) Impact of Syrian Refugees on the Jordanian Labor Market, Geneva: ILO.

Vila, P. (2000) Crossing borders, reinforcing borders: Social categories, metaphors, and narrative identities on the US-Mexico frontier. Austin: University of Texas Press.

Wilkes, R., and Wu, C. (2019) Immigration, discrimination, and trust: A simply complex relationship. Frontiers in Sociology 4, Article 32.

Williamson, S., Adida, C., Lo, A., Platas, M., Prather, L., and Werfel, S. (2020) Increasing immigrant inclusion: Family history, empathy, and immigration in the United States. Mimeo. 


\section{ONLINE APPENDIX}

\section{A Additional Figures}

Figure A.1: Distribution of responses to questions discussed in Table 2
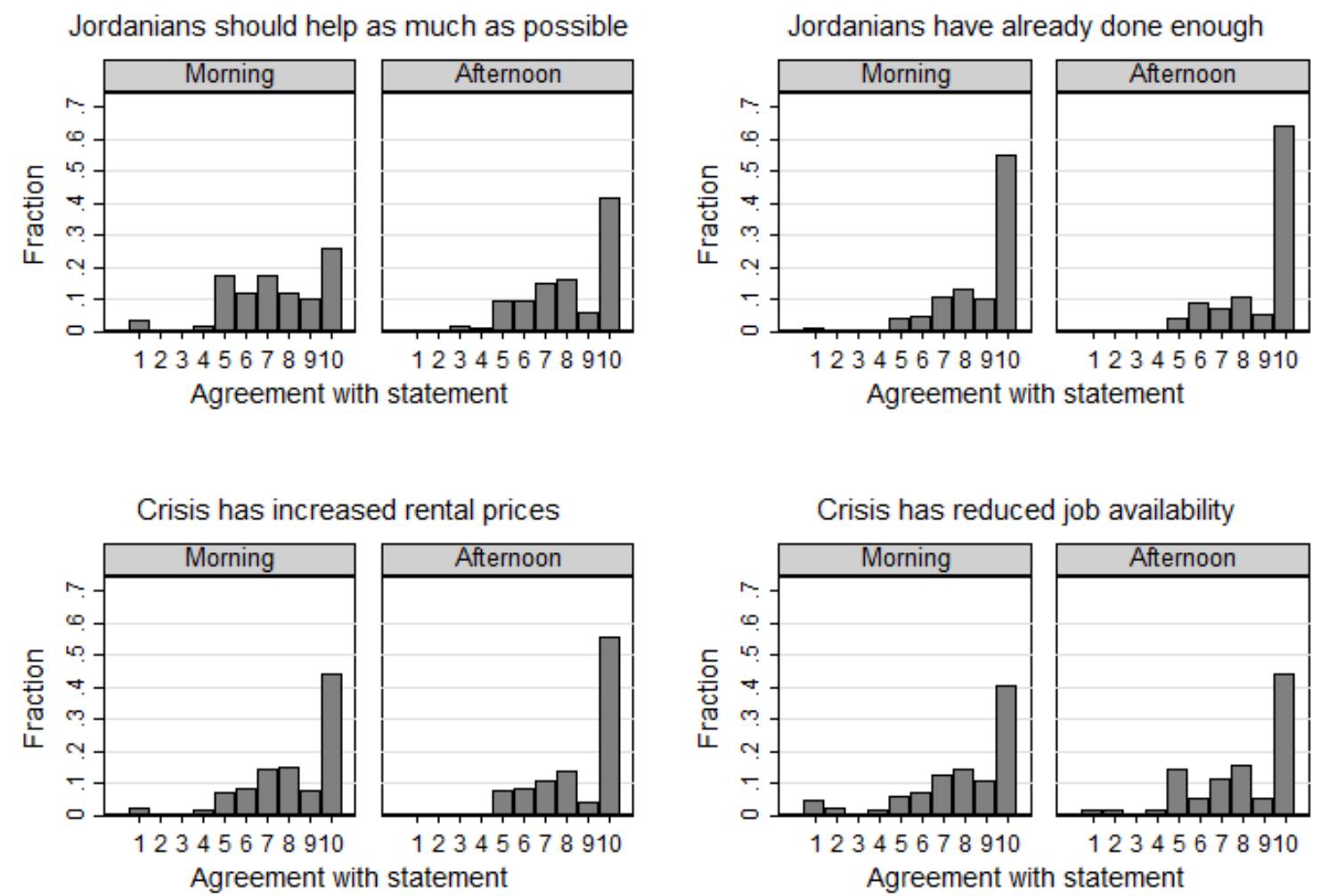

Agreement with statement coded from 1 (totally disagree) to 10 (totally agree). 


\section{B Sample Version of the Instructions (Morning Shift, First Sharing Task with Morning Shift, No Salience of Group Identity)}

General instructions for the enumerator are italicized

[(Sub-)Headings and information not to be read out loud are written in brackets]

Hello, my name is XY. The participation in this game is voluntary. I will explain you how it works and then ask you, if you want to participate - is that fine for you? (If child wants to hear the instructions, go on with instructions; if child wants to stop already now, then bring the child back to the classroom and enter the child's decision appropriately into the tablet).

In the four games we play today, you will get some gifts. Depending on your decisions, other children will also get some gifts. Those gifts I will put into these envelopes later (show the three envelopes; one for the participant, one for a child from the same shift and one for a child from the other shift); and you will get your gifts at the end of the shift; but I will explain you all details later. Now let me first write your name on the one where I will store your gifts (write participant's name + father's name + family name + grade + ' $M^{\prime} /{ }^{\prime} A$ ' (depending on shift) on his / her envelope; also label other envelopes with ' $M$ ' and ' $A$ ', but do not talk about the meaning of the ' $M$ ' and ' $A$ ' yet). One gift I will put in the envelope right now, this you can keep irrespective of whether you participate or not (put big toy in the envelope).

\section{[Game 1]}

In this game you can earn gifts. This is the gift you receive in this game (show participant gift for the first game). You will receive your gifts after this shift. More details I will explain to you later.

[The partner]

In the first part of this game you can send gifts to another child who attends school in your shift at your own school. The other child is randomly selected from another class. Your partner is a child of about your age. Your partner does not know who exactly you are.

\section{[The Game]}

The first part of the game works as follows: (lay down the first card (labelled 'Card 1 - green: Games 1 and 2') on the table, place grey and green playing pieces on them) On this card you can see your partner (point to the partner's playing piece). As I told you before, you may earn gifts in this game. But only you get five gifts at the beginning (five gifts for the first game are placed in front of the grey playing piece corresponding to the participating child) that you can share with your partner. Your partner does not get any gifts that she or he can share with you. Therefore, you will not receive any gifts from your partner, as they have nothing to share with you. You have to decide how many gifts you want to take for yourself and how many gifts you want to send to your partner. That means you have to decide, whether you would like to send ZERO, ONE, TWO, THREE, FOUR or FIVE of your gifts to your partner, who attends school in the same 
shift as you do (the morning shift) (when listing the possibilities of decision making, use the gifts to illustrate). If you want to send for example TWO gifts, then you have to move two of the gifts to your partner (move two gifts to the other playing piece). In that case you send two gifts away (two gifts from the own (grey) playing piece are pushed away to the middle), and your partner receives those two gifts (now place the two gifts next to the other playing piece). You will keep three gifts. Can you tell me what happens if you would like to send FOUR gifts to your partner? (reallocate the gifts to get the original allocation; the participant has to explain: (i) participant sends four gifts away (ii) partner gets four gifts (iii) participant keeps one gift) And what happens if you send nothing? (the participant has to explain: (i) participant sends no gift away (ii) partner gets nothing (iii) participant keeps all five gifts)

Your partner really exists and will receive the gifts at the end of this shift; therefore I have an envelope for your partner here as well (show the envelope for the corresponding partner). We will put your gifts in an envelope that you will get at the end of the shift.

[Understanding]

Now let's see what you can still remember. Could you please repeat the rules concerning the gifts in your own words, what can you do with them and what happens? (Participant has to repeat: (i) the participant can send between zero and five gifts to the partner (ii) the partner receives those gifts, the participant will keep the remaining gifts and not receive any gifts from the partner; if the participant does not repeat all the points alone, then ask questions)

Can you please repeat when and how you get your gifts today in your own words? (Participant has to repeat: (i) the participant gets the gifts in the envelope labelled with his / her name after the shift; (ii) the partner also gets gifts in the corresponding envelope).

Do you also remember who your partner is? (The following points have to be repeated: (i) the partner is randomly selected (ii) the partner attends school in the same shift (the morning shift), but in another class (iii) The partner is represented by a green playing piece (iv) the partner is about the same age as the participant $(v)$ the participant receives no other information on the partners ( $v i)$ the partners do not know the identity of the child; if the participant does not repeat all the points alone, then ask questions).

[Consent]

Okay, now tell me: Do you want to participate? (If child wants to participate go on with the instructions; if child does not want to participate then bring the child back to the classroom and enter the child's decision appropriately into the tablet).

[The Decision]

Good, then you can make your decision (point at the card laying on the table). Remember that your partner attends school in the same shift as you do (the morning shift). It is very important that your decisions are secret. Your partner will not know that it was you who was deciding in 
this game, they will just receive the envelope. The decision is your secret. Now please take as much time as you need for your decision. I will turn around in the meantime so that you are not disturbed. Call me when you are ready (when participant calls, turn towards the participant).

[After the decision]

(After the decision the enumerator has to check if the child took a valid decision. If something is wrong, ask participant to correct. Enter decision into the tablet (this is Game 1) and put the gifts in the appropriate envelope: gifts allocated to the participant into the envelope labelled with his / her name and gifts allocated to the partner into a not yet used envelope for either the morning or the afternoon shift, depending on when the partner attends school).

Thank you for your decision. Now I have a question. How many gifts do you think would your partner send to you, if she or he had received five gifts from us to play the game you just played? (Enter answer into the tablet (this is Game 1))

\section{[Game 2]}

Okay, now let's play another game.

[The partner]

The game works exactly the same as with your partner before. The only difference is that now you play with another partner and that you can earn different gifts. Now you can earn those gifts (show participant gift for the second game). First we need another playing card (lay down the other playing card for Game 1/Game 2 (labelled 'Card 1 - blue: Games 1 and 2') on the table, place grey and blue playing pieces on them) The partner you are now playing with (point at the partner's playing piece) is a child who attends school in the other shift, i.e. the afternoon shift, and we use a blue playing piece for her / him. As before, your partner is randomly selected and does not know who exactly you are.

[The game]

Ok, and do you remember the rules of the game? (If participant is unsure or hesitates, ask if anything should be explained again or quickly repeat: (i) the participant can send between zero and five gifts to the partner (ii) the partner receives those gifts, the participant will keep the remaining gifts and not receive any gifts from the partner)

As before, your partner really exists and will receive the gifts at the end of this shift; therefore I also have an envelope for this partner here (show the envelope for the corresponding partner) [Understanding]

And can you repeat who your partner is?

(The following point has to be repeated: the partner attends school in the other shift, i.e. the afternoon shift, and is represented by a blue playing piece; if the participant does not the point alone, then ask questions).

[Decision] 
Good, then you can make your decision. Remember that your partner attends the other shift, i.e. the afternoon shift and that it is very important that your decisions are secret. Your partner will not know that it was you who was deciding in this game, they will just receive the envelope. The decision is your secret. Now please take as much time as you need for your decision. I will turn around in the meantime so that you are not disturbed. Call me when you are ready (when participant calls, turn towards the participant).

[After the decision]

(After the decision the enumerator has to check if the child took a valid decision. If something is wrong, ask participant to correct. Enter decision into the tablet (this is Game 2) and put the gifts in the appropriate envelope: gifts allocated to the participant into the envelope labelled with his / her name and gifts allocated to the partner into a not yet used envelope for either the morning or the afternoon shift, depending on when the partner attends school).

Thank you for your decision. Now I again have a question. How many gifts do you think would your partner in this second part send to you, if she or he had received gifts from us to play the game you just played? (Enter answer into the tablet (this is Game 2))

\section{[Game 3]}

Now let's play another game. In this game, you have to distribute gifts between two other children, but you cannot keep any of those gifts for yourself. Because this is a challenging task, you get five gifts of those gifts yourself - irrespective of how you distribute the gifts between your partners (show participant the gifts for the third game). Look, I am putting the five gifts into your envelope now. [put five gifts into the envelope with the participant's name written on it]

\section{[The partners]}

We have the same two partners from the last two games, the one from your shift, and the one from the other shift (lay down the second card (labelled 'Card 2: Game 3') on the table):

Here is the green playing piece, and here is the blue playing piece (playing pieces are placed in front of the participant on the second card on their corresponding positions).

As before, the green playing piece (point to the green playing piece) is for your partner from before who attends school in your shift, i.e. the morning shift, and the blue partner (point to the blue playing piece) is for your partner from before who attends school in the other shift, i.e. the afternoon shift.

[The game]

The game works as follows:

On this card you can see a green playing piece for the partner from your shift and a blue playing piece for the partner from the other shift (point to the green and blue playing pieces). This means that you are now deciding for your green and blue partners. Five gifts (five gifts are 
placed between the green playing piece and the blue playing piece) have to be distributed between your green and your blue partners.

The distribution of gifts works exactly as before, only that you now distribute gifts between your green and your blue partner.

[Understanding]

Okay, so can you please repeat what you will get in this game, what you have to do and what that means to your partners? (The following points have to be repeated:

(i) the child will earn five gifts for taking a decision on behalf of the others, that is (ii) distributing the five gifts between them (iii) recipients of the gifts that the participant has to distribute will be other children).

And do you still remember who your partners are? (If participant is unsure or hesitates, repeat the following points:

(i) the partner with the green playing piece attends school the same shift, i.e. the morning shift

(ii) the partner with the blue playing piece attends school in the other shift, i.e. the afternoon shift

[Decision]

Now you can make your decisions (point at the card on the table with the green and blue playing pieces). Remember that your green partner (point to the green playing piece) attends school in your shift, i.e. the morning shift, and that your blue partner (point to the blue playing piece) attends school in the other shift, i.e. the afternoon shift. It is very important that your decisions are secret. Your partners will not know that it was you who was deciding in this game, they will just receive the envelopes. The decision is your secret.

Please take as much time as you need for your decisions. I will turn around in the meantime so that you are not disturbed. Call me when you are ready (when participant calls, turn towards the participant).

[After the decision]

(After the decision the enumerator has to check if the child took a valid decision. If something is wrong, ask participant to correct. Enter decision into the tablet (this is Game 3) and put the gifts in the appropriate envelope: gifts allocated to each partner into their envelopes that have been used for them before).

Thank you for your decision. 